\title{
PENGARUH KETIDAKLENGKAPAN BERKAS REKAM MEDIS TERHADAP PELAPORAN DATA MORBIDITAS PASIEN RAWAT INAP (RL4a) DI RSU MITRA MEDIKA MEDAN
}

\author{
1. Tri Widya Sandika; ${ }^{2 .}$ Sopyah Anggraini \\ 1. Dosen Prodi D-III Perekam Dan Infokes Imelda, Jalan Bilal Nomor 52 Medan; ${ }^{2}$ Mahasiswa STIKes \\ Imelda Medan
}

E-mail: ${ }^{1 .}$ triwidyasandika.tri306@gmail.com
2. $\underline{\text { sopyahanggraini08@gmil.com }}$

\begin{abstract}
ABSTRAK
Ketidaklengkapan berkas rekam medis rawat inap merupakan masalah yang sangat penting karena berpengaruh terhadap mutu pelayanan kesehatan pada rumah sakit. Tujuan penelitian ini adalah untuk mengetahui Pengaruh Ketidaklengkapan Berkas Rekam Medis Rawat Inap terhadap pelaporan Data Morbiditas Pasien rawat Inap (RLAa) di RSU Mitra Medika Medan Tahun 2019. Jenis penelitian ini dengan deskriptif kuantitatif. Populasi penelitian sebanyak 1252 berkas rekam medis rawat inap dengan penentuan sampel sebanyak 100 berkas. Hasil penelitian menunjukkan bahwa dari 100 berkas rekam medis rawat inap dengan 2 item yang telah ditentukan dalam setiap berkas, pengisian berkas rekam medis secara lengkap terdapat pada item identitas sebanyak 81 berkas (81\%) dan tidak lengkap sebanyak 19 berkas (19\%). Pada item diagnosa pengisian lengkap sebanyak 77 berkas (77\%) dan tidak lengkap sebanyak 23 berkas (23\%). Dari hasil persentase tersebut peneliti menyimpulkan jika pengisian berkas rekam medis kurang lengkap, maka pelaporan data morbiditas pasien rawat inap (Rl4a) akan menghasilkan data yang kurang baik.
\end{abstract}

Kata Kunci $\quad$ : Rekam Medis, Pelaporan Data Morbiditas Pasien Rawat Inap (RLAa)

\section{PENDAHULUAN}

Menurut Undang-Undang Nomor 44 (2009), Rumah Sakit adalah institusi pelayanan kesehatan per orangan secara komprehensif yang menyediakan pelayanan rawat inap, rawat jalan dan gawat darurat. Dalam melakukan pelayanan kesehatan di rumah sakit sangat diperlukan pencatatan yang baik dan benar yang terakomodasi di dalam rekam medis.

Rekam medis keterangan baik yang tertulis maupun yang terekam tentang identitas, anamnese penentuan fisik laboratorium, diagnosa segala pelayanan dan tindakan medis yang diberikan kepada pasien dan pengobatan baik yang rawat inap, rawat jalan maupun yang mendapatkan pelayanan gawat darurat (Rustiyanto, 2014).

Rekam medis di dalam sarana pelayanan kesehatan rumah sakit mempunyai peran yang sangat penting dalam memberikan informasi dan dapat melaksanakan kegiatan untuk melakukan pencatatan dan pendokumentasian terhadap berkas rekam medis pasien. Rekam medis adalah berkas yang berisikan catatan dan dokumen tentang identitas pasien, pemeriksaan, pengobatan, tindakan dan pelayanan lain yang telah diberikan kepada pasien. Kegunaan rekam medis medis dibagi menjadi 7 aspek yaitu aspek administrasi, aspek medis, aspek hukum, aspek keuangan, aspek penelitian, aspek pendidikan dan aspek dokumentasi, karena isinya menyangkut sumber ingatan yang harus didokumentasikan dan dipakai sebagai bahan pertanggungjawaban dan laporan rumah sakit (Kemenkes, 2011).

Sesuai ketentuan pasal 52 ayat (1) Undang-Undang Nomor 44 tahun 2009, setiap rumah sakit wajib melakukan 
pencatatan dan pelaporan tentang semua kegiatan penyelenggaraan rumah sakit dalam bentuk sistem informasi manajemen rumah sakit. Pencatatan dan pelaporan yang dilakukan oleh rumah sakit dilakukan dalam rangka meningkatkan efektivitas pelayanan.

Berdasarkan Peraturan Menteri

Kesehatan Republik Indonesia Nomor 1171/Menkes/Per/VI/2011 setiap rumah sakit wajib melaksanakan Sistem Informasi Kesehatan Rumah Sakit (SIRS). SIRS merupakan aplikasi sistem rumah sakit yang terdiri dari proses pengumpulan, pengolahan dan penyajian data rumah sakit kepada Kementrian Kesehatan yang meliputi data identitas rumah sakit, data ketenagaan yang bekerja di rumah sakit, data rekapitulasi kegiatan pelayanan, data kompilasi penyakit/morbiditas pasien rawat inap, dan data kompilasi penyakit/morbiditas pasien rawat jalan.

Pelaporan SIRS terdiri dari pelaporan yang terbarukan setiap saat (update) dan pelaporan yang bersifat periodi. Pelaporan SIRS yang bersifat terbarukan setiap saat (update) ditetapkan berdasarkan kebutuhan informasi untuk pengembangan program dan kebijakan dalam bidang perumahsakitan. Salah satu pelaporan yang bersifat periodik yaitu data keadaan morbiditas dan mortalitas pasien rawat inap (RL4a) dilaksanakan setiap tahun oleh masing-masing rumah sakit berdasarkan laporan harian yang dikompilasi setiap bulannya

(Kemenkes, 2011).

Sistem pelaporan rumah sakit (SIRS) adalah suatu sistem yang dibuat oleh departemen kesehatan yang bertujuan mendapatkan data tentang segala kegiatan rumah sakit diseluruh Indonesia yang kemudian dijadikan informasi tentang keadaan kesehatan nasional. Dikarenakan pentingnya sistem pelaporan ini, maka sudah menjadi keharusan bahwa setiap rumah sakit di Indonesia memberikan laporan sesuai dengan jadwal yang telah ditetapkan (Kemenkes, 2011).

Berdasarkan survey awal yang dilakukan di RSU Mitra Medika Medan, terdapat beberapa masalah yaitu ketidaklengkapan berkas rekam medis rawat inap yang menyebabkan waktu pelaporan data morbiditas pasien rawat inap (RL4a) belum mencapai tujuan yang diharapkan.

Sesuai analisa 30 berkas rekam medis rawat inap di RSU Mitra Medika, menunjukkan bahwa pada item pengisian identitas terdapat sebanyak 15 berkas $(50 \%)$ pengisian lengkap dan 15 berkas (50\%) tidak lengkap. Selanjutanya pada item Diagnosa sebanyak 13 berkas (43\%) lengkap dan 17 berkas (56\%) tidak lengkap.

Berdasarkan uraian permasalahan di atas, maka penulis tertarik untuk melakukan penelitian mengenai "Pengaruh Ketidaklengkapan Berkas Rekam Medis Terhadap Pelaporan Data Morbiditas Pasien Rawat Inap (RL4a) Di RSU Mitra Medika Medan Tahun 2019".

\section{Rumusan Masalah}

Sesuai dengan uraian yang dijelaskan pada latar belakang di atas, permasalahan dalam penelitian ini adalah: Bagaimana Pengaruh Ketidaklengkapan Berkas Rekam Medis Terhadap Pelaporan Data Morbiditas Pasien Rawat Inap (RL4a) Di RSU Mitra Medika Medan Tahun 2019 ?

\section{Tujuan Penelitian}

Untuk mengetahui penyebab dan pengaruhketidaklengkapan berkas rekam medis pasien rawat inap di RSU Mitra Medika Medan.

\section{Manfaat Penelitian}

1. Bagi Rumah Sakit

Sebagai kajian bagi intern rumah sakit untuk meminimalisasikan ketidaklengkapan berkas rekam medis sehingga pelaporan data morbiditas pasien rawat inap dapat berjalan dengan lebih efisien dan efektif.

2. Bagi Intitusi Pendidikan

Sebagai bahan kajian yang berguna untuk pengembangan pendidikan dan sebagai bahan referensi dalam pengembangan ilmu rekam medis.

\section{METODE}

\section{Jenis Penelitian}

Jenis penelitian ini menggunakan metode penelitian deskriptif kuantitatif. 
Metode penelitian deskriptif adalah suatu metode penelitian yang dilakukan dengan tujuan utama untuk menjelaskan tentang faktor ketidaklengkapan berkas rekam medis rawat inap untuk pelaporan data morbiditas pasien rawat inap (RL4a) di RSU Mitra Medika Medan Tahun 2019.

\section{Waktu Penelitian}

Penelitian dilakukan pada bulan Februari sampai Mei 2019.

\section{Tempat Penelitian}

Tempat yang dipilih penelitian ini dilakukan di RSU Mitra Medika Medan di Jl. KL Yos Sudarso No.KM.7,5, Tj. Mulia, Alasan memilih Rumah Sakit Mitra Medika sebagai tempat penelitian karena dapat dijangkau dan menemukan kasus yang sesuai dengan yang ingin diteliti oleh peneliti.

\section{Populasi}

Populasi adalah keseluruhan objek penelitian atau objek yang akan diteliti (Notoatmodjo, 2012). populasi dalam penelitian ini adalah seluruh berkas rekam medis rawat inap bulan Februari sampai dengan Mei 2019 sebanyak 1252 berkas

\section{Sampel dan Teknik Sampling}

Sampel adalah objek yang diteliti dan dianggap mewakili seluruh populasi (Notoatmodjo, 2012). Sampel dalam penelitian ini ditentukan oleh peneliti sebanyak 100 berkas.

\section{Instrumen Penelitian}

Instrumen penelitian adalah alat yang digunakan oleh peneliti dalam mengumpulkan data agar pekerjaannya lebih mudah dan hasilnya lebih baik (Arikunto,2012). Dalam instrumen penelitian ini adalah menggunakan lembar observasi.

\section{Sumber Data} yaitu:

Adapun sumber data yang digunakan

1. Data primer

Data primer diperoleh langsung dari petugas rekam medis melalui wawancara dan dari hasil observasi.

2. Data sekunder

Data sekunder adalah data yang sudah ada yaitu profil rumah sakit, data BPJS, kebijakan dan SOP yang ada di rumah sakit.

\section{Analisis Data \\ Data dalam penelitian ini dianalisa secara deskriftif adalah memaparkan hasil penelitian apa adanya dan membandingkan dengan teori yang kemudian diambil kesimpulan. Dalam data ini teknik pengolahan data secara analisis yang dilakukan terhadap variabel dari hasil penelitian ini yang bertujuan untuk menjelaskan setiap variabel penelitian. Adapun penyajian hasil penelitian ini dalam bentuk uraian kalimat dan tabulasi (Notoatmodjo, 2012).}

\section{HASIL}

\section{Ketidak Lengkapan Berkas Rekam Medis}

Tabel 1. Ketidak Lengkapan Berkas Rekam Medis Januari - Mei 2019

\begin{tabular}{|c|c|c|c|c|c|}
\hline \multirow[t]{2}{*}{ No } & \multirow{2}{*}{$\begin{array}{l}\text { No. } \\
\text { RM }\end{array}$} & \multicolumn{2}{|c|}{ Identitas } & \multicolumn{2}{|c|}{ Diagnosa } \\
\hline & & $\begin{array}{c}\text { Lengk } \\
\text { ap }\end{array}$ & $\begin{array}{c}\text { Tidak } \\
\text { Leng } \\
\text { kap }\end{array}$ & $\begin{array}{l}\text { Leng } \\
\text { kap }\end{array}$ & $\begin{array}{c}\text { Tidak } \\
\text { Leng } \\
\text { kap }\end{array}$ \\
\hline 1 & & $\sqrt{ }$ & & & $\sqrt{ }$ \\
\hline 2 & & $\sqrt{ }$ & & $\sqrt{ }$ & \\
\hline 3 & & & $\sqrt{ }$ & $\sqrt{ }$ & \\
\hline 4 & & $\sqrt{ }$ & & & $\sqrt{ }$ \\
\hline 5 & & $\sqrt{ }$ & & $\sqrt{ }$ & \\
\hline 6 & & $\sqrt{ }$ & & $\sqrt{ }$ & \\
\hline 7 & & $\sqrt{ }$ & & & $\sqrt{ }$ \\
\hline 8 & & & $\sqrt{ }$ & $\sqrt{ }$ & \\
\hline 9 & & $\sqrt{ }$ & & & $\sqrt{ }$ \\
\hline 10 & & $\sqrt{ }$ & & $\sqrt{ }$ & \\
\hline 11 & & $\sqrt{ }$ & & $\sqrt{ }$ & \\
\hline 12 & & $\sqrt{ }$ & & & $\sqrt{ }$ \\
\hline 13 & & & $\sqrt{ }$ & $\sqrt{ }$ & \\
\hline 14 & & $\sqrt{ }$ & & $\sqrt{ }$ & \\
\hline 15 & & $\sqrt{ }$ & & $\sqrt{ }$ & \\
\hline 16 & & & $\sqrt{ }$ & $\sqrt{ }$ & \\
\hline 17 & & $\sqrt{ }$ & & $\sqrt{ }$ & \\
\hline 18 & & $\sqrt{ }$ & & & $\sqrt{ }$ \\
\hline
\end{tabular}




\begin{tabular}{|c|c|c|c|c|}
\hline 19 & $\sqrt{ }$ & & & $\sqrt{ }$ \\
\hline 20 & & $\sqrt{ }$ & $\sqrt{ }$ & \\
\hline 21 & $\sqrt{ }$ & & $\sqrt{ }$ & \\
\hline 22 & $\sqrt{ }$ & & $\sqrt{ }$ & \\
\hline 23 & $\sqrt{ }$ & & & $\sqrt{ }$ \\
\hline 24 & $\sqrt{ }$ & & $\sqrt{ }$ & \\
\hline 25 & $\sqrt{ }$ & & & $\sqrt{ }$ \\
\hline 26 & & $\sqrt{ }$ & $\sqrt{ }$ & \\
\hline 27 & 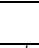 & $\sqrt{ }$ & $\sqrt{ }$ & \\
\hline 28 & $\sqrt{ }$ & & & $\sqrt{ }$ \\
\hline 29 & $\sqrt{ }$ & & $\sqrt{ }$ & \\
\hline 30 & $\sqrt{ }$ & & $\sqrt{ }$ & \\
\hline 31 & & $\sqrt{ }$ & $\sqrt{ }$ & \\
\hline 32 & $\sqrt{ }$ & & $\sqrt{ }$ & \\
\hline 33 & $\sqrt{ }$ & & 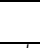 & $\sqrt{ }$ \\
\hline 34 & $\sqrt{ }$ & & $\sqrt{ }$ & \\
\hline 35 & & $\sqrt{ }$ & $\sqrt{ }$ & \\
\hline 36 & $\sqrt{ }$ & & $\sqrt{ }$ & \\
\hline 37 & & $\sqrt{ }$ & $\sqrt{ }$ & \\
\hline 38 & $\sqrt{ }$ & & $\sqrt{ }$ & \\
\hline 39 & $\sqrt{ }$ & & 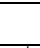 & $\sqrt{ }$ \\
\hline 40 & $\sqrt{ }$ & & $\sqrt{ }$ & \\
\hline 41 & $\sqrt{ }$ & & $\sqrt{ }$ & \\
\hline 42 & & $\sqrt{ }$ & $\sqrt{ }$ & \\
\hline 43 & $\sqrt{ }$ & & $\sqrt{ }$ & \\
\hline 44 & & $\sqrt{ }$ & $\sqrt{ }$ & \\
\hline 45 & & $\sqrt{ }$ & $\sqrt{ }$ & \\
\hline 46 & $\sqrt{ }$ & & 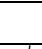 & $\sqrt{ }$ \\
\hline 47 & $\sqrt{ }$ & & $\sqrt{ }$ & \\
\hline 48 & $\sqrt{ }$ & & & $\sqrt{ }$ \\
\hline 49 & $\sqrt{ }$ & & . & $\sqrt{ }$ \\
\hline 50 & $\sqrt{ }$ & & $\sqrt{ }$ & \\
\hline 51 & $\sqrt{ }$ & & $\sqrt{ }$ & \\
\hline 52 & $\sqrt{ }$ & & 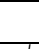 & $\sqrt{ }$ \\
\hline 53 & $\sqrt{ }$ & & $\sqrt{ }$ & \\
\hline 54 & $\sqrt{ }$ & & $\sqrt{ }$ & \\
\hline 55 & & $\sqrt{ }$ & $\sqrt{ }$ & \\
\hline 56 & $\sqrt{ }$ & & $\sqrt{ }$ & \\
\hline 57 & $\sqrt{ }$ & & $\sqrt{ }$ & \\
\hline 58 & $\sqrt{ }$ & & & $\sqrt{ }$ \\
\hline 59 & $\sqrt{ }$ & & 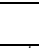 & $\sqrt{ }$ \\
\hline 60 & & $\sqrt{ }$ & $\sqrt{ }$ & \\
\hline 61 & $\sqrt{ }$ & & $\sqrt{ }$ & \\
\hline 62 & $\sqrt{ }$ & & $\sqrt{ }$ & \\
\hline 63 & $\sqrt{ }$ & & $\sqrt{ }$ & \\
\hline 64 & $\sqrt{ }$ & & & $\sqrt{ }$ \\
\hline 65 & $\sqrt{ }$ & & 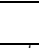 & $\sqrt{ }$ \\
\hline 66 & $\sqrt{ }$ & & $\sqrt{ }$ & \\
\hline 67 & $\sqrt{ }$ & & $\sqrt{ }$ & \\
\hline 68 & $\sqrt{ }$ & & 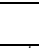 & $\sqrt{ }$ \\
\hline 69 & $\sqrt{ }$ & & $\sqrt{ }$ & \\
\hline 70 & & $\sqrt{ }$ & $\sqrt{ }$ & \\
\hline 71 & & $\sqrt{ }$ & $\sqrt{ }$ & \\
\hline 72 & $\sqrt{ }$ & & $\sqrt{ }$ & \\
\hline 73 & $\sqrt{ }$ & & $\sqrt{ }$ & \\
\hline
\end{tabular}

\begin{tabular}{|c|c|c|c|c|}
\hline 74 & $\sqrt{ }$ & & $\sqrt{ }$ & \\
\hline 75 & $\sqrt{ }$ & & $\sqrt{ }$ & \\
\hline 76 & $\sqrt{ }$ & & $\sqrt{ }$ & \\
\hline 77 & $\sqrt{ }$ & & $\sqrt{ }$ & \\
\hline 78 & $\sqrt{ }$ & & $\sqrt{ }$ & \\
\hline 79 & $\sqrt{ }$ & & $\sqrt{ }$ & \\
\hline 80 & $\sqrt{ }$ & & $\sqrt{ }$ & \\
\hline 81 & & $\sqrt{ }$ & $\sqrt{ }$ & \\
\hline 82 & $\sqrt{ }$ & & $\sqrt{ }$ & \\
\hline 83 & $\sqrt{ }$ & & & $\sqrt{ }$ \\
\hline 84 & $\sqrt{ }$ & & $\sqrt{ }$ & \\
\hline 85 & $\sqrt{ }$ & & $\sqrt{ }$ & \\
\hline 86 & $\sqrt{ }$ & & $\sqrt{ }$ & \\
\hline 87 & $\sqrt{ }$ & & $\sqrt{ }$ & \\
\hline 88 & $\sqrt{ }$ & & $\sqrt{ }$ & \\
\hline 89 & $\sqrt{ }$ & & $\sqrt{ }$ & \\
\hline 90 & $\sqrt{ }$ & & . & $\sqrt{ }$ \\
\hline 91 & $\sqrt{ }$ & & $\sqrt{ }$ & \\
\hline 92 & $\sqrt{ }$ & & $\sqrt{ }$ & \\
\hline 93 & $\sqrt{ }$ & & $\sqrt{ }$ & \\
\hline 94 & $\sqrt{ }$ & & $\sqrt{ }$ & \\
\hline 95 & $\sqrt{ }$ & & $\sqrt{ }$ & \\
\hline 96 & $\sqrt{ }$ & & $\sqrt{ }$ & \\
\hline 97 & $\sqrt{ }$ & & $\sqrt{ }$ & \\
\hline 98 & & $\sqrt{ }$ & $\sqrt{ }$ & \\
\hline 99 & $\sqrt{ }$ & & $\sqrt{ }$ & \\
\hline 100 & $\sqrt{ }$ & & $\sqrt{ }$ & \\
\hline Total & 81 & 19 & 77 & 23 \\
\hline
\end{tabular}

Berdasarkan Tabel 1 diatas diketahui bahwa dari 100 berkas rekam medis pasien rawat inap dengan 2 item yang telah ditentukan dalam setiap berkas, pengisian berkas rekam medis dengan lengkap terdapat pada item Identitas sebanyak 81 berkas (81\%) dan tidak lengkap sebanyak 19 berkas (19\%). Pada item Diagnosa pengisian lengkap sebanyak 77 berkas (77\%) dan tidak lengkap sebanyak 23 berkas (23\%).

\section{Pelaporan data RI4a (Data Keadaan Morbiditas Pasien Rawat Inap) di RSU Mitra Medika Medan}

Berdasarkan hasil penelitian yang dilakukan di RSU Mitra Medika Medan, pelaporan data morbiditas rekam medis pasien rawat inap dilakukan dalam waktu triwulan. Pada saat berkas rekam medis diasembling sering terdapat ketidaklengkapan berkas rekam medis di bagian diagnosa pasien yang tidak dilengkapi oleh dokter, dan berkas rekam medis yang tidak lengkap tersebut 
dikembalikan keruangan untuk dilengkapi dengan diberi jangka waktu 3hari, kejadian seperti ini membuat pelaporan data morbiditas terlambat dan dilaporkan dengan digabungkan dengan pelaporan data morbiditas triwulan selanjutnya.

\section{PEMBAHASAN}

\section{Ketidaklengkapan Berkas Rekam Medis Pasien Rawat inap}

Ketidaklengkapan berkas adalah ketidaklengkapan yang dilakukan oleh petugas kesehatan di rumah sakit yang memberikan pelayanan pada pasien. Ketidaklengkapan berkas rekam medis merupakan masalah yang sangat penting karena dapat berpengaruh terhadap proses pelayanan yang dilakukan oleh petugas medis dan mempengaruhi kualitas dari mutu pelayanan suatu rumah sakit (Shofari Bambang, 2000).

Berdasarkan hasil pengamatan (observasi) berkas rekam medis pasien rawat inap bahwa sebagian besar pengisian item Identitas dengan lengkap, yaitu $81 \%$ dan sebagian sebagian besar pengisian item Diagnosa dengan lengkap, yaitu $77 \%$.

Penyebab ketidaklengkapan pengisian berkas rekam medis rawat inap ini adalah kurangnya tenaga rekam medis di rumah sakit. Didapatkan juga bahwa prosedur tentang pengisisian berkas rekam medis yang ada tidak yang lengkap dan mengakibatkan kurang adanya standar tetap dalam pengisian rekam medis..

Setelah peneliti melakukan penelitian, solusi yang dapat diambil dalam masalah ketidaklengkapan berkas rekam medis adalah agar petugas diruangan lebih teliti dalam melakukan analisa berkas rekam medis, apabila berkas rekam medis ditemukan tidak ada tertulis diagnosa akhir dilembar resume, maka petugas ruangan seharusnya cepat mengkonsultasikan kepada dokter yang bersangkutan. Sehingga pelaporan morbiditas pasien rawat inap dilaporkan dengan tepat waktu sesuai dengan ketentuan yang sudah ditetapkan oleh Dinas Kesehatan.

\section{Pelaporan data morbiditas pasien rawat inap (RI4a) di RSU Mitra Medika Medan}

Formulir RL4a adalah formulir untuk data keadaan morbiditas pasien rawat inap yang merupakan formulir rekapitulasi dari jumlah pasien keluar dari rumah sakit (Hidup dan Mati) untuk periode tahunan (Kemenkes, 2011).

Dari hasil persentase ketidaklengkapan berkas rekam medis pasien rawat inap dari 100 berkas yang diobservasi dengan 2 item yakni identitas dan diagnosa menunjukkan bahwa ketidaklengkapan pengisian berkas rekam medis pasien rawat inap sebagian besar lengkap. Dari hasil persentase tersebut peneliti menyimpulkan jika pengisian berkas rekam medis belum lengkap, maka pelaporan data morbiditas pasien rawat inap (R14a) tidak bisa dilakukan tepat waktu ke Dinas Kesehatan. Hal ini berdasarkan hasil observasi yang dilakukan oleh peneliti di RSU Mitra Medika Medan.

Setelah peneliti melakukan penelitian, solusi yang dapat peneliti ambil dalam masalah pelaporan data morbiditas pasien rawat inap adalah meningkatkan kedisiplinan para pegawai rekam medis, petugas ruangan rawat inap maupun dokter yang mengisi diagnosa untuk mengisi lengkap berkas rekam medis terutama bagian identitas dan diagnosa pasien sesuai dengan ketentuan yang diterapkan pada peraturan rumah sakit tersebut, meningkatkan pelatihan pengetahuan tentang pentingnya kelengkapan berkas rekam medis terhadap pelaporan data morbiditas pasien rawat inap.

\section{KESIMPULAN}

Kesimpulan yang dapat peneliti peroleh dari hasil penelitian adalah sebagai berikut:

1. Hasil penelitian mengenai Pengaruh Ketidaklengkapan Berkas Rekam Medis Terhadap Pelaporan Data Morbiditas Pasien Rawat Inap (R14a) di RSU Mitra Medika Medan, terdapat sebagian besar pengisian item Identitas pada berkas rekam medis rawat inap dengan lengkap sebanyak 81 berkas (81\%). Berkas rekam medis yang lengkap ditemukan dari analisa pemeriksaan berkas rekam medis 
pasien rawat inap yang sudah diisi secara lengkap oleh dokter dan perawat yang bertugas diruangan rawat inap.

2. Hasil penelitian mengenai Pengaruh Ketidaklengkapan Berkas Rekam Medis Terhadap Pelaporan Data Morbiditas Pasien Rawat inap (R14a) di RSU Mitra Medika Medan, terdapat sebagian besar pengisian item Diagnosa pada berkas rekam medis rawat inap dengan lengkap sebanyak 77 berkas (77\%), disebabkan karena kurang telitinya petugas ruangan dan dokter yang mengisi diagnosa akhir di lembar resume pasien. Sebaiknya petugas ruangan lebih teliti dan mengingatkan dokter dalam melakukan pengisian diagnosa akhir di lembar resume pasien, Karena bahan acuan untuk pembuatan laporan Data Morbiditas Pasien Rawat Inap (RL4a) harus menggunakan diagnosa akhir.

\section{SARAN}

\section{Rumah Sakit}

Disarankan bagi pimpinan rumah sakit lebih memotivasi tenaga kesehatan agar melakukan pekerjaannya lebih baik lagi sehingga mampu memberikan hasil pelaporan data morbiditas pasien rawat inap sesuai dengan jangka waktu yang telah ditetapkan.

\section{Institusi Pendidikan}

Disarankan bagi institusi pendidikan agar lebih meningkatkan mutu pendidikan kesehatan untuk memproduksi tenaga kesehatan yyang profesional dan mumpuni di bidangnya.

\section{Peneliti Selanjutnya}

Disarankan penelitian ini dapat menjadi referensi untuk peneliti selanjutnya yang mempunyai masalah yang sama dengan penelitian ini.

\section{DAFTAR PUSTAKA}

Adisasmito, Wiku. (2009). Sistem Manajemen Lingkungan Rumah Sakit. Jakarta: Rajawali Press.

Notoatmodjo, Soekidjo. (2012). Pengembangan Sumber Daya Manusia. Jakarta: Rineka Cipta.

Peraturan Menteri Kesehatan Republik Indonesia Nomor 512/Menkes/ PER/IV/2007 Tentang Izin Praktik dan Pelaksanaan Praktik Kedokteran.

Septiani, Resti Nurdiah, Arief Tarmansyah Iman. (2016). Analisis Penyebab Unclaimed Berkas BPJS Rawat Inap di RSUD Dr. Soekardjo Tasikmalaya. Jurnal Manajemen Informasi Kesehatan Indonesia Vol. 4 No.2 Oktober 2016 ISSN: 2337-6007 (online); 2337-585X (Printed).

Saryono dan Mekar S.A. (2013). Metodologi Penelitian Kualitatif dan Kuntitatif Dalam Bidang Kesehatan. Yogyakarta: Nuha Medika.

Syafrudin. (2009). Organisasi Dan Manajemen Pelayanan Kesehatan. Jakarta-Timur: Trans Info Media

Undang-undang No. 24 Tahun 2011. Badan Penyelenggara Jaminan Sosial.

Undang-Undang No. 40 Tahun 2004. Sistem Jaminan Sosial Nasional (SJSN).

Peraturan Menteri Kesehatan Republik Indonesia Nomor 27 Tahun 2014 Tentang Petunjuk Teknis Sistem Indonesian Case Base Groups (INACBGs). 